\title{
Evaluation of Risk of Building Damage due to Deep Excavations via Numerical Modelling
}

\author{
Xingxing Zhang $\mathbb{D}^{1}$ and Zhifeng Zhan $\mathbb{D}^{2}$ \\ ${ }^{1}$ School of Civil Engineering, Chongqing University of Arts and Sciences, Chongqing 402160, China \\ ${ }^{2}$ Independent Consultant, Chongqing, China \\ Correspondence should be addressed to Zhifeng Zhan; zhifengzhan@163.com
}

Received 11 November 2020; Revised 1 May 2021; Accepted 4 June 2021; Published 1 July 2021

Academic Editor: Yixian Wang

Copyright ( $) 2021$ Xingxing Zhang and Zhifeng Zhan. This is an open access article distributed under the Creative Commons Attribution License, which permits unrestricted use, distribution, and reproduction in any medium, provided the original work is properly cited.

\begin{abstract}
In the densely populated urban environment, ground movements induced by deep excavations inevitably present a risk of damage to adjacent buildings and structures. An important and necessary aspect to justify the engineering design is to evaluate the degree of risk of such damage. This paper presents a specific procedure to evaluate the engineering design by assessing the risk level of building damage based on the deformation profiles along the ground surface which are calculated via numerical modelling and verified by empirical methods. This procedure is afterwards applied to justify the engineering design of the extension line construction of a metro project between PK0 +344.00 and PK0 +407.00 with the cut-and-cover excavation method. The results demonstrate that the damage risk levels of all the buildings adjacent to the excavations are within category level 0 indicating that the relevant design is acceptable while considering the risk of building damage induced by deep excavations.
\end{abstract}

\section{Introduction}

The engineering design for deep excavations usually involves design factors such as the construction sequences, structure planning, drainage scheme, detailed structural design for supporting structures, and instrumentation system. Analyses of stress and deformation, internal and external stability, water flow, and piping are normally required in order to justify the relevant design strategy. One of the important considerations in this justification is to keep the displacements induced by deep excavations within acceptable limits because deep excavations in urban zones inevitably cause ground movements which may induce damages to adjacent buildings and structures. Supporting structures such as diaphragm walls and struts are usually set up in order to minimise possible building damage due to deep excavations in urban situations.

Therefore, it is necessary, both for engineering design and for planning and consultation, to develop rational methods to assess the risks of damage. A rational approach to the assessment of risk of damage to buildings due to deep excavations was developed and adopted during the planning and enquiry stages of the London Underground Jubilee Line Extension project which involved tunnelling under densely developed areas of central London [1,2]. This approach includes three stages of damage assessment: preliminary assessment, second stage assessment, and detailed evaluation.

So as to avoid complex and unnecessary calculations, the preliminary phase uses a very simple and conservative method for the evaluation of damage level based on the contours of expected ground surface movements. In the second stage, the equivalent beam approach [3] is adopted to estimate the maximum tensile strain and establish a certain category of damage for the potentially affected buildings. The third stage of detailed evaluation is only performed for buildings that are classified as being at high risk of damage. This approach has been widely used internationally with minor variations. This paper mainly focuses on the second stage of this approach.

A specific procedure to justify the engineering design is established in this paper as described in the following four 
steps: (1) prediction of the magnitude and distribution of ground movements behind diaphragm walls; (2) selection of appropriate damage criterion; (3) assessment of risk level of building damage under selected criterion based on known ground deformation profiles; (4) justification of engineering design according to the results of ground movements and risk assessment.

The proposed engineering design of deep excavations is accepted only if the ground movements and risk level of damage are within the range of engineering safety. Otherwise, the design strategy should be modified and evaluated again through the 4 steps. This process should be repeated until the eventual design is judged to be acceptable.

In step 1, the calculation of ground movements is not straight forward because of the complexity of the problem which is critically dependent both on the ground conditions (e.g., stratigraphy, groundwater conditions, deformation, and strength properties) and the method of construction (e.g., sequence of excavation, sequence of propping, rigidity of diaphragm wall, and supports). To estimate the likely damage, both the lateral ground movements and the settlement trough caused by the excavation must first be estimated. Recently, the development of advanced computational tools allows delicate calculation of these ground movements induced by deep excavations via numerical modelling. In this paper, both empirical and advanced numerical methods are presented. The latter method is preferred in consideration that it has been widely used for prediction of ground movements around deep excavations and can simulate the construction process, modelling the various stages of excavation and support conditions. Meanwhile, the comparison of numerical results with those obtained through empirical method is made to verify mutually the respective results from both methods.

As for the damage criterion, different theories are reviewed and analysed to select the damage criterion. The details will be described later in this paper. This specific procedure is then applied to justify the engineering design of the extension line construction of a metro project from PK0 +344.00 to PK0 +407.00 with the cut-and-cover excavation method by assessing the risk of building damage via numerical modelling.

\section{Estimation and Calculation of Ground Movement Induced by Excavation}

The response of buildings adjacent to deep excavations refers to the translation and rotation of building structure in reaction to lateral ground movements and surface settlement. Proper assessment of risk of building damage requires an accurate prediction of the magnitude and distribution of ground movements adjacent to an excavation via empirical and advanced numerical methods.

\subsection{Empirical Methods for Estimating Ground Movements.} The research of Peck [4] accounting for varying soil types and depths provided the first rational basis for estimating general ground movements resulting from an adjacent excavation. Clough and O'Rourke [5] developed well-defined excavation-induced settlement profiles by plotting the various settlement data as fractions of the maximum settlement for sand, stiff to very hard clays, and soft to medium clays.

Hsieh and $\mathrm{Ou}$ [6] developed a semiempirical method to predict the distribution of ground movements based upon previous research including Peck [4] and Clough and O'Rourke [5]. Two types of settlement profiles due to excavations were suggested: (1) the spandrel type with maximum settlement distributed very close to the wall and (2) the concave type with maximum settlement located at some distance away from the diaphragm wall. At the first stage of excavation, the spandrel type of settlement profile occurs if a large amount of wall deflection takes place under cantilever conditions. After the initial stages of excavation, additional cantilever wall deflection is restrained by installation of support as the excavation proceeds to deeper elevations and the concave type dominates the settlement profile with the maximum lateral deformation occurring near the bottom of the excavation.

Figure 1 presents the graphical methods for predicting settlement profiles of both the spandrel and concave conditions developed by Hsieh and $\mathrm{Ou}$ [6]. This figure was based on case history data compiled by Clough and O'Rourke [5] and the evaluation of case history data from Taipei, Taiwan.

The "mean estimate" curve shown in Figure 1(a) was adopted for the settlement profile prediction. Figure 1(a) plots the square root of the distance from the edge of the excavation $(d)$ normalized by the excavation depth $\left(H_{e}\right)$ versus the normalized settlement $\left(\delta_{v} / \delta_{\mathrm{vm}}\right) . \delta_{v}$ represents the settlement at some location while $\delta_{\mathrm{vm}}$ represents the maximum ground surface settlement.

Figure 1(b) plots the normalized distance from the edge of the wall versus the normalized settlement. Hsieh and $\mathrm{Ou}$ [6] concluded that the distance from the support wall to the point where the maximum ground surface settlement occurred was approximately equal to half of the excavated depth $\left(H_{e} / 2\right)$. The settlement at the diaphragm wall location was half of the maximum settlement $\left(\delta_{\mathrm{vm}}\right)$. The point on the settlement profile curve marked by $d / H_{e}=2$ corresponds to the extent of the primary influence zone. The settlement was practically negligible at a distance from the support wall equal to four times the depth of the excavation $\left(4 H_{e}\right)$.

\subsection{Numerical Methods for Calculating Ground Movements.} The building response due to deep excavations is dependent upon factors such as the stiffness of the excavation support system, the installation procedures of the system, the soil conditions, the excavation procedures, the type of building, the distance of the building from the excavation, the orientation of the building with respect to the excavation, and the size of the building with respect to the excavation. A purely theoretical approach to estimate building response due to excavation-related deformations is not possible due to the variability of these factors that contribute to the response. However, with the rapid innovation of computer technology, the numerical methods and relevant computer 


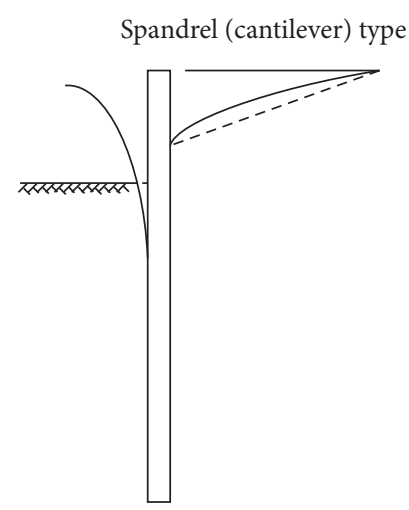

$\left(d / H_{e}\right)^{1 / 2}$

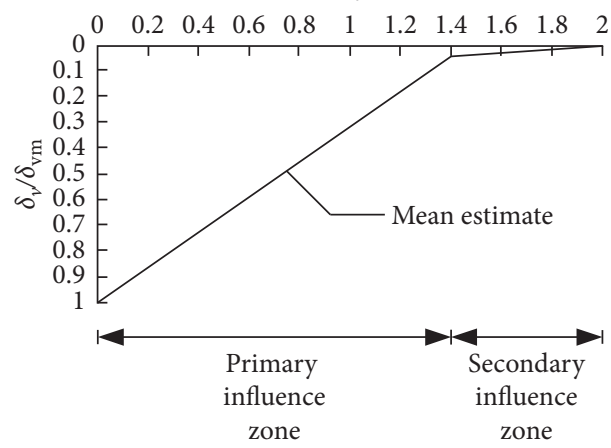

(a)
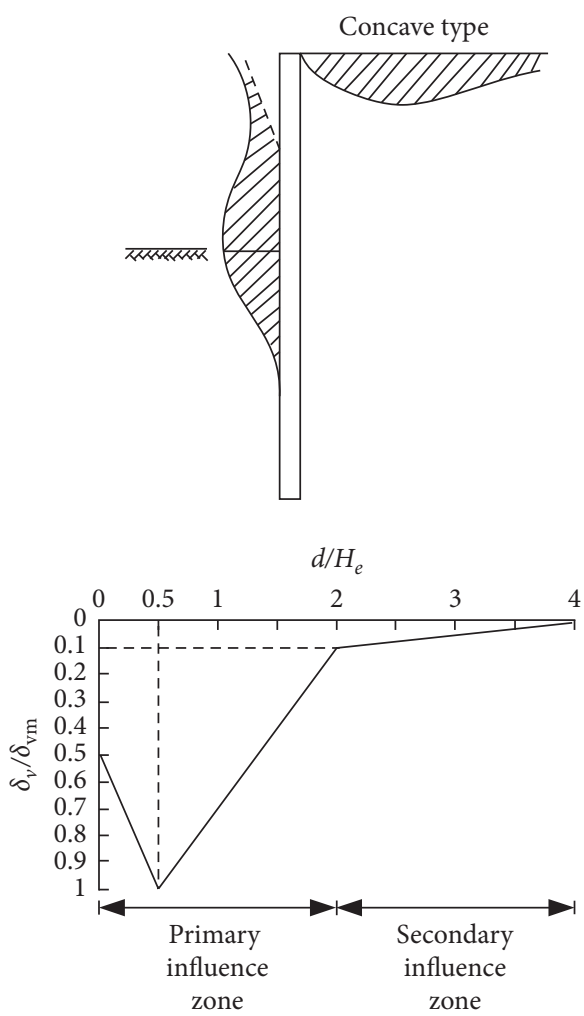

(b)

Figure 1: Empirical methods for predicting both spandrel and concave settlement profiles [6].

programs are available to take the mentioned factors into account.

Numerical simulations using the finite element method and finite difference method with the aforementioned advantages are progressively replacing simplified traditional calculation methods-limit equilibrium method and Winkler's theory. Software applications such as PLAXIS, ABAQUS, CRISP, ICFEP, MIDAS GTS, Z-SOIL (finite element method), and FLAC (finite difference method) are widely utilized to perform such numerical simulations. Schweiger [7-13] presented in detail the results from a numerical benchmark exercise addressing the design of a diaphragm wall for a deep excavation problem by using PLAXIS. Comprehensive study was performed to analyse the influence of various modelling parameters including domain analysed, stiffness of structural elements, soil-structure interface, constitutive model, etc. As stated by Schweiger [7-13], one of the critical factors is the constitutive model adopted to simulate the soil behavior. It has been confirmed that the generally used elastic-perfectly plastic constitutive model (Mohr-Coulomb model) or any other that incorporates a linear elastic component is not well suited for predicting realistic deformations for deep excavation problems. The main defects lie in the following: (1) although reasonable wall lateral movements can be obtained by using the Mohr-Coulomb model, computed settlements are often in error; (2) excavation bottom heave is considerably overestimated; and (3) the location of the lower boundary of the calculation domain has a decisive influence on computed displacements. It was also demonstrated by comparison with field data that constitutive models allowing for nonlinearity of the stress-strain curve can give both reasonable wall deflection and realistic ground movements. The hardening soil model is one such model which is being applied widely in recent years to deal with similar problems. It is accordingly adopted in the subsequent case study.

In this paper, FLAC3D [14] is chosen as the numerical tool to carry out the calculations of ground movements. The detailed creation of numerical models involving all the model parameters via FLAC3D is beyond the scope of this paper and can be referred to Itasca [14].

\section{Criteria for Assessing Building Damage}

3.1. Definitions of Excavation-Induced Deformations Related to Building Response. The translations and rotations of building adjacent to excavations result in direct tensile strains, bending strains, and diagonal tensile strains in building structures. A consistent set of definitions describing types of ground movements and building responses based on the displacements (either measured or calculated) of a number of discrete points on the foundations of a building was proposed by Burland and Wroth [3] and summarized by Finno and Alvello [15]. These definitions (illustrated in 
Figure 2) have been widely accepted and are described as follows:

(a) Settlement (downward displacement) or heave (upward displacement) is denoted as $S$.

(b) Relative settlement (differential settlement or differential heave) is denoted as $\delta S$.

(c) Rotation or slope is the change in gradient of a line joining two reference points (e.g., $\mathrm{AB}$ in Figure 2). Rotation is typically used to describe the slope of the settlement trough.

(d) The angular strain $\alpha$ is defined in Figure 2. It is positive for upward concavity (sagging seen in Figure 3) and negative for downward concavity (hogging seen in Figure 3).

(e) Relative deflection $\Delta$ is the displacement of a point relative to the line connecting two reference points on either side (see Figure 2). The sign convention is the same as (d).

(f) Deflection ratio (sagging ratio or hogging ratio) is denoted by $\Delta / L$ where $L$ is the distance between the two reference points defining $\Delta$. The sign convention is the same as (d) and (e). The deflection ratio is an approximate measure of curvature of the settlement curve and is often correlated with bending related distortions in a structure.

(g) Tilt $\omega$ describes the rigid body rotation of the structure or a well-defined part of it (see Figure 2).

(h) Relative rotation (angular distortion) $\beta$ is the rotation of the line joining two points, relative to the tilt $\omega$ (see Figure 2).

(i) Average horizontal strain $\varepsilon_{h}$ is defined as the change of length $\delta L$ over the length $L$ and is used to describe the direct lateral movement of building structures. It is customary to take a reduction of length (compression) as positive in soil mechanics.

The above definitions only apply to in-plane deformations and no attempt has been made to define three-dimensional behavior.

3.2. Damage Criteria Based on Angular Distortion. Damage criteria based on angular distortion have been developed by Skempton and MacDonald [16], Polshin and Tokar [17], Bjerrum [18], O'Rourke et al. [19], and Attewell et al. [20]. Bjerrum [18] took the angular distortion as the governing variable in the assessment of permissible deformations. Typical limiting values of angular distortion for buildings where only building settlement is assessed are shown in Figure 4.

Damage criteria based on angular distortion do not consider the horizontal displacement. But ground movements related to deep excavations can include a substantial component of horizontal strain except vertical deformation. Therefore, the traditional criteria based on differential settlement or angular distortion alone is inadequate for assessment of building response due to deep excavations.

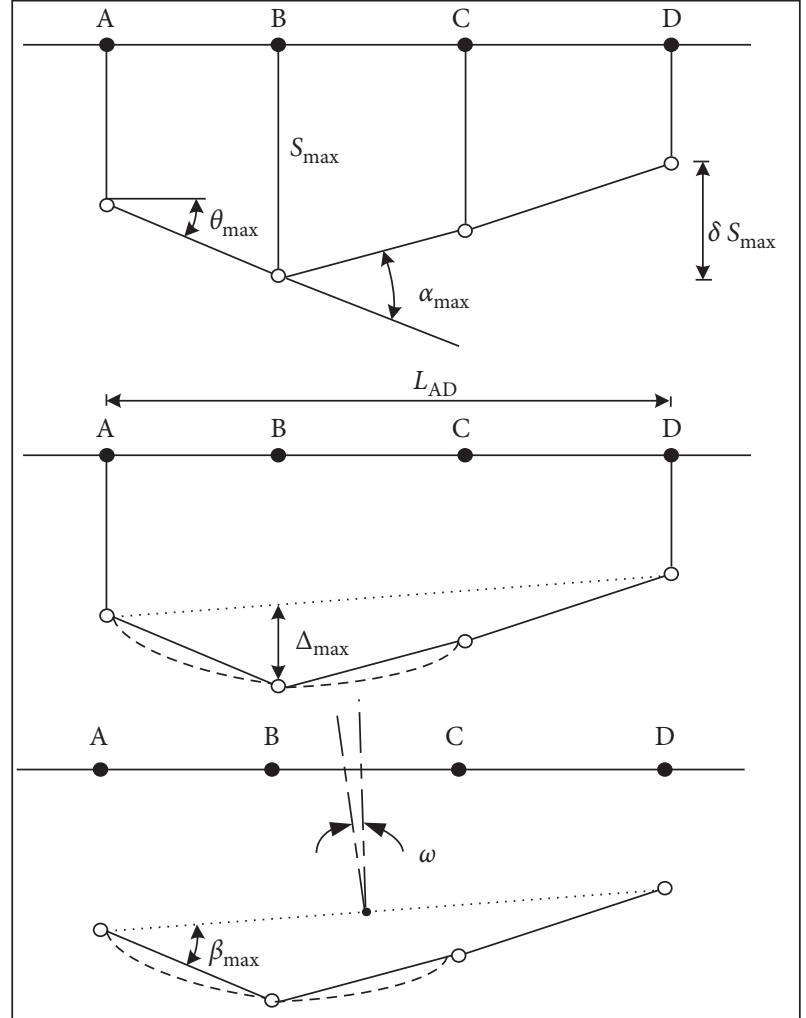

Figure 2: Definitions of ground and foundation movement [3].

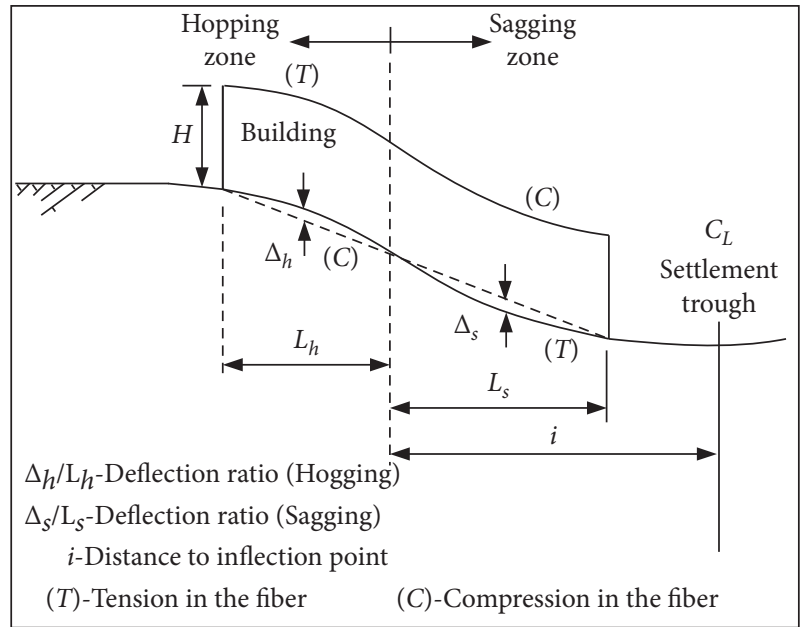

FIGURE 3: Deflection mode of building in response to deformation [3].

\subsection{Damage Criteria Proposed by Boscardin and Cording [21] and Burland et al. [22]}

3.3.1. Concept of Limiting Tensile Strain $\varepsilon_{\lim }$ and Classification of Building Damage. Cracking in masonry walls and finishes usually, but not always, results from tensile strain. Burland and Wroth [3] firstly defined critical tensile strain $\varepsilon_{\text {crit }}$ with which the onset of visible cracking in building is associated. Burland and Wroth [3] also showed how the concept of critical tensile strain could be used in conjunction 


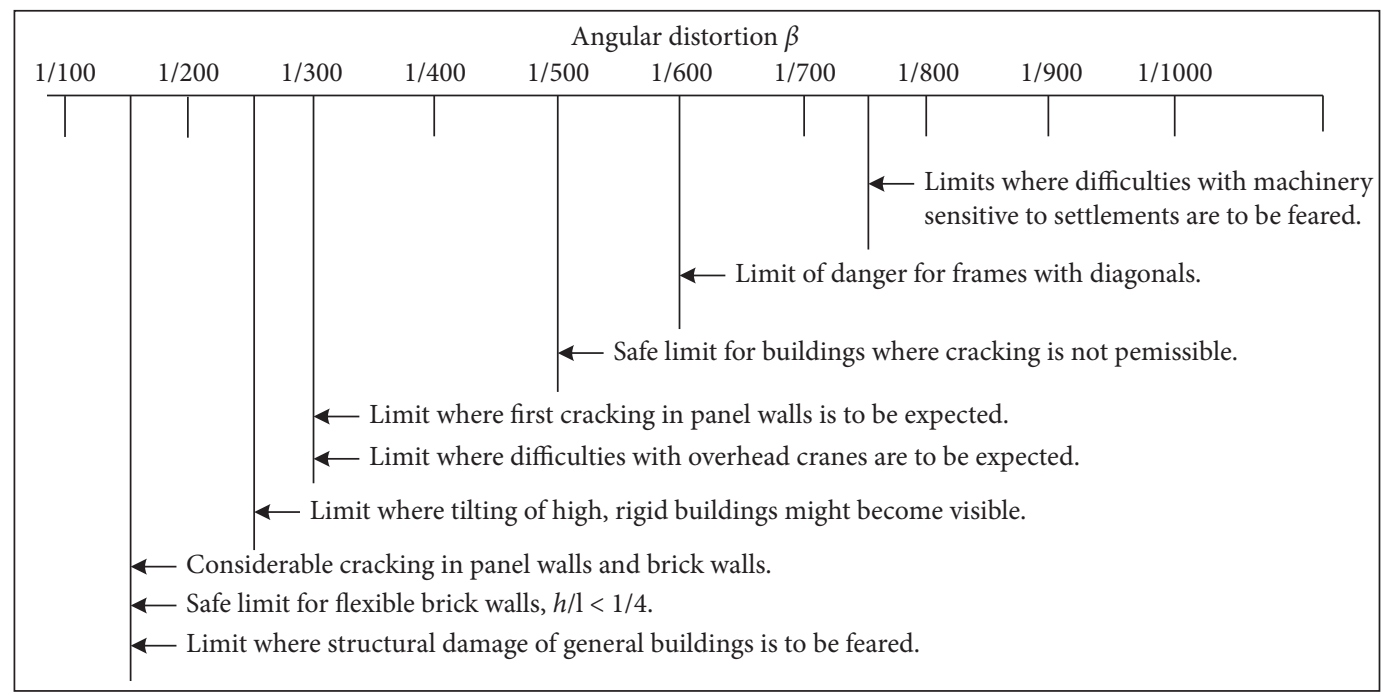

FIgURE 4: Limiting angular distortion [18].

with simple elastic beams to develop deflection criteria for the onset of visible damage. Burland et al. [23] introduced the concept of limiting tensile strain $\varepsilon_{\text {lim }}$ to replace critical tensile strain $\varepsilon_{\text {crit }}$ as a serviceability parameter which can be varied to take account of differing material and serviceability limit states. Boscardin and Cording [21] developed this concept by assessing 17 case records of damage due to excavation-induced subsidence. They related the ranges of $\varepsilon_{\lim }$ to the likely severity of damage. Burland [24] summarized the categories of building damage as shown in Table 1 which provides the link between estimated building deformations and the possible severity of damage.

Burland et al. [22] introduced the term "the level of risk" of damage to refer to the possible degree of damage as defined in Table 1. Most buildings with degree of damage within the first three categories 0 to 2 (i.e., negligible to slight) are considered to be at "low risk" and can be readily and economically repaired. A major objective of design and construction is to maintain the level of risk below the threshold between categories 2 and 3 for all buildings.

3.3.2. Equivalent Beam Approach to Evaluate Building Damage. Burland and Wroth [3] introduced the equivalent beam approach in the evaluation of damage to buildings due to ground movements where the building is represented by an elastic rectangular deep beam of length $L$ and height $H$ (Figure 5). This approach is to calculate the tensile strains in the beam for a given deflected shape of the building foundations and hence obtain the deflection ratio $\Delta / L$ at which cracking is initiated. Burland and Wroth [3] considered two extreme modes: bending only about a neutral axis at the center and shearing only. In the case of bending only, the cracks are related to the bending strain $\varepsilon_{b}$ occurring in the top fibre, whereas in the case of shearing only the diagonal cracks are due to the shear strain $\varepsilon_{d}$ caused by shear deformations. In general, both modes of deformation will occur simultaneously and it is necessary to calculate both bending and shear strains to ascertain which type is limiting.
Timoshenko [25] put up the expression for the total midspan deflection $\Delta / L$ of a central point loaded beam with the maximum bending strain $\varepsilon_{b \max }$ and the maximum shear strain $\varepsilon_{d \max }$ as follows:

$$
\begin{aligned}
& \frac{\Delta}{L}=\left(\frac{L}{12 h}+\frac{3 I}{2 h L H} \frac{E}{G}\right) \varepsilon_{b \max } \\
& \frac{\Delta}{L}=\left(1+\frac{H L^{2}}{18 I} \frac{G}{E}\right) \varepsilon_{d \max }
\end{aligned}
$$

where $h$ is the distance of the neutral axis from the edge of the beam in tension ( $h=H$ for hogging and $h=H / 2$ for sagging); $E$ is Young's modulus; $G$ is the shear modulus; and $I$ is the second moment of area $\left(I=H^{3} / 3\right.$ for hogging and $I=H^{3} / 12$ for sagging).

By setting $\varepsilon_{\max }=\varepsilon_{\text {lim }}$, equations (1) and (2) define the limiting values of $\Delta / L$ for the deflection of simple beams. For a given deflection ratio $\Delta / L$, an estimation of the maximum tensile strain in the building can be obtained as the maximum of the values of $\varepsilon_{b \text { max }}$ and $\varepsilon_{d \text { max }}$ provided by equations (1) and (2).

Burland and Wroth [3] showed that generally hogging is much more damaging than sagging-a result that is well borne out in practice. Figure 6 presents the limiting relationships between $\Delta / L$ normalized by $\varepsilon_{\lim }$ and $L / H$ for an isotropic beam undergoing hogging $(E / G=2.6$ and $\left.I=H^{3} / 3\right)$ with its neutral axis at the bottom edge $(h=H / 2)$ and undergoing sagging $\left(E / G=2.6\right.$ and $\left.I=H^{3} / 12\right)$ with its neutral axis at the middle $(h=H / 2)$. It can be seen that the shear strains dominate if $L / H<1.3$, whereas for $L / H>1.3$, the bending strains dominate.

Boscardin and Cording [21] incorporated horizontal extension strain $\varepsilon_{h}$, which excavations can induce, in the above analysis through simple superposition of this effect to Burland and Wroth's [3] bending and shear strains.

For the case of bending, the resultant extreme fibre strain $\varepsilon_{b r}$ is given by 
TABLE 1: Building damage classification [22].

\begin{tabular}{|c|c|c|c|c|}
\hline $\begin{array}{l}\text { Category } \\
\text { level }\end{array}$ & $\begin{array}{c}\text { Normal degree } \\
\text { of severity }\end{array}$ & Description of typical damage & $\begin{array}{l}\text { Approximate crack width } \\
(\mathrm{mm})\end{array}$ & $\begin{array}{l}\text { Limiting tensile } \\
\text { strain } \varepsilon_{\lim }(\%)\end{array}$ \\
\hline 0 & Negligible & Hairline cracks & $0-0.1$ & $0-0.05$ \\
\hline 1 & Very slight & Fine cracks easily treated during normal decoration & $0.1-1$ & $0.05-0.075$ \\
\hline 2 & Slight & $\begin{array}{l}\text { Cracks easily filled. Several slight fractures inside building. } \\
\text { Exterior cracks visible. }\end{array}$ & $1-5$ & $0.075-0.15$ \\
\hline 3 & Moderate & $\begin{array}{c}\text { Cracks may require cutting out and patching. Door and } \\
\text { windows sticking. }\end{array}$ & $\begin{array}{l}5-15 \text { (or several closely } \\
\text { spaced cracks }>3 \mathrm{~mm} \text { ) }\end{array}$ & $0.15-0.3$ \\
\hline 4 & Severe & $\begin{array}{l}\text { Extensive repair involving removal and replacement of } \\
\text { walls, especially over doors and windows. Windows and } \\
\text { door frames distorted. Floor slopes noticeably. }\end{array}$ & $\begin{array}{l}15-25 \text { (but also depends } \\
\text { on number of cracks) }\end{array}$ & $>0.3$ \\
\hline 5 & Very severe & $\begin{array}{l}\text { Major repair required involving partial or complete } \\
\text { reconstruction. Danger of instability. }\end{array}$ & $\begin{array}{l}>25 \text { (but also depends on } \\
\text { number of cracks) }\end{array}$ & $>0.3$ \\
\hline
\end{tabular}

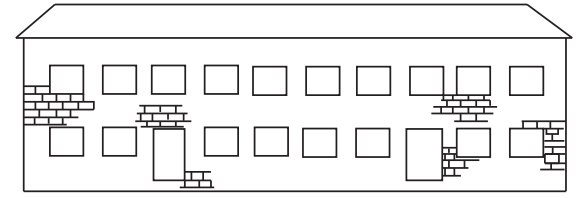

(a)

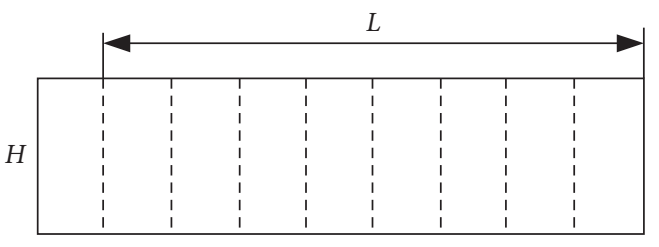

(c)

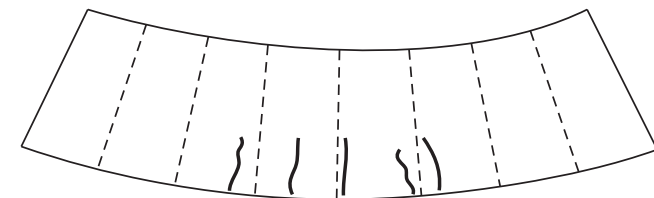

(b)

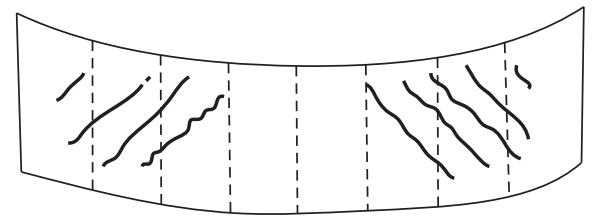

(d)

$\checkmark \Delta$

(e)

FIGURE 5: The equivalent beam approach [22]. (a) Actual building. (b) Bending deformation with cracking due to direct tensile strain. (c) Beam: simple idealisation of building. (d) Shear deformation with cracking due to diagonal tensile strain. (e) Deflected shape of soffit of beam.

$$
\varepsilon_{b r}=\varepsilon_{b \max }+\varepsilon_{h} .
$$

In the shearing region, the resultant shear strain $\varepsilon_{d r}$ can be evaluated using Mohr's circle of strain and is given by

$$
\varepsilon_{d r}=\varepsilon_{h} \frac{1-v}{2}+\sqrt{\varepsilon_{h}^{2}\left(\frac{1+v}{2}\right)^{2}+\varepsilon_{d \max }^{2}},
$$

where $v$ is Poisson's ratio.

The maximum tensile strain is greater than $\varepsilon_{b r}$ and $\varepsilon_{d r}$ and can be used in conjunction with Table 1 to assess the potential associated damage.

3.3.3. Damage Criterion Proposed by Burland et al. [22]. By adopting the values of $\varepsilon_{\lim }$ associated with the various categories of damage given in Table 1 and by using equations (1)-(4), a building damage interaction diagram can be developed showing the relationship between $\Delta / L$ and $\varepsilon_{h}$ for appropriate values of $h, L / H, E / G, v$, and $I$ selected for the structure being assessed. The physical implications of equations (1)-(4) can be illustrated by considering an isotropic beam with $v=0.3\left(E / G=2.6\right.$ and $\left.I=H^{3} / 12\right)$ undergoing hogging $(h=H)$. For bending case, manipulation of equations (1) and (3) with $\varepsilon_{b r}=\varepsilon_{\lim }$ gives

$$
\frac{(\Delta / L)}{\varepsilon_{\lim }}=\left(0.083 \frac{L}{H}+1.3 \frac{H}{L}\right)\left(1-\frac{\varepsilon_{h}}{\varepsilon_{\lim }}\right) .
$$

For shearing, manipulation of equations (2) and (4) with $\varepsilon_{d \max }=\varepsilon_{\lim }$ yields

$$
\frac{(\Delta / L)}{\varepsilon_{\lim }}=\left(1+0.064\left(\frac{L}{H}\right)^{2}\right) \sqrt{1-0.7 \frac{\varepsilon_{h}}{\varepsilon_{\lim }}-0.3\left(\frac{\varepsilon_{h}}{\varepsilon_{\lim }}\right)^{2}} .
$$

The relationships between $\Delta / L$ and $\varepsilon_{h}$ normalized by $\varepsilon_{\text {lim }}$ given by equations (5) and (6) are shown in Figure 7 . It is evident from Figure 7 that $L / H$ determines the shape of the damage interaction diagram for isotropic beams undergoing hogging. The damage interaction diagram corresponding to $L / H=1$ is presented in Figure 8 . 


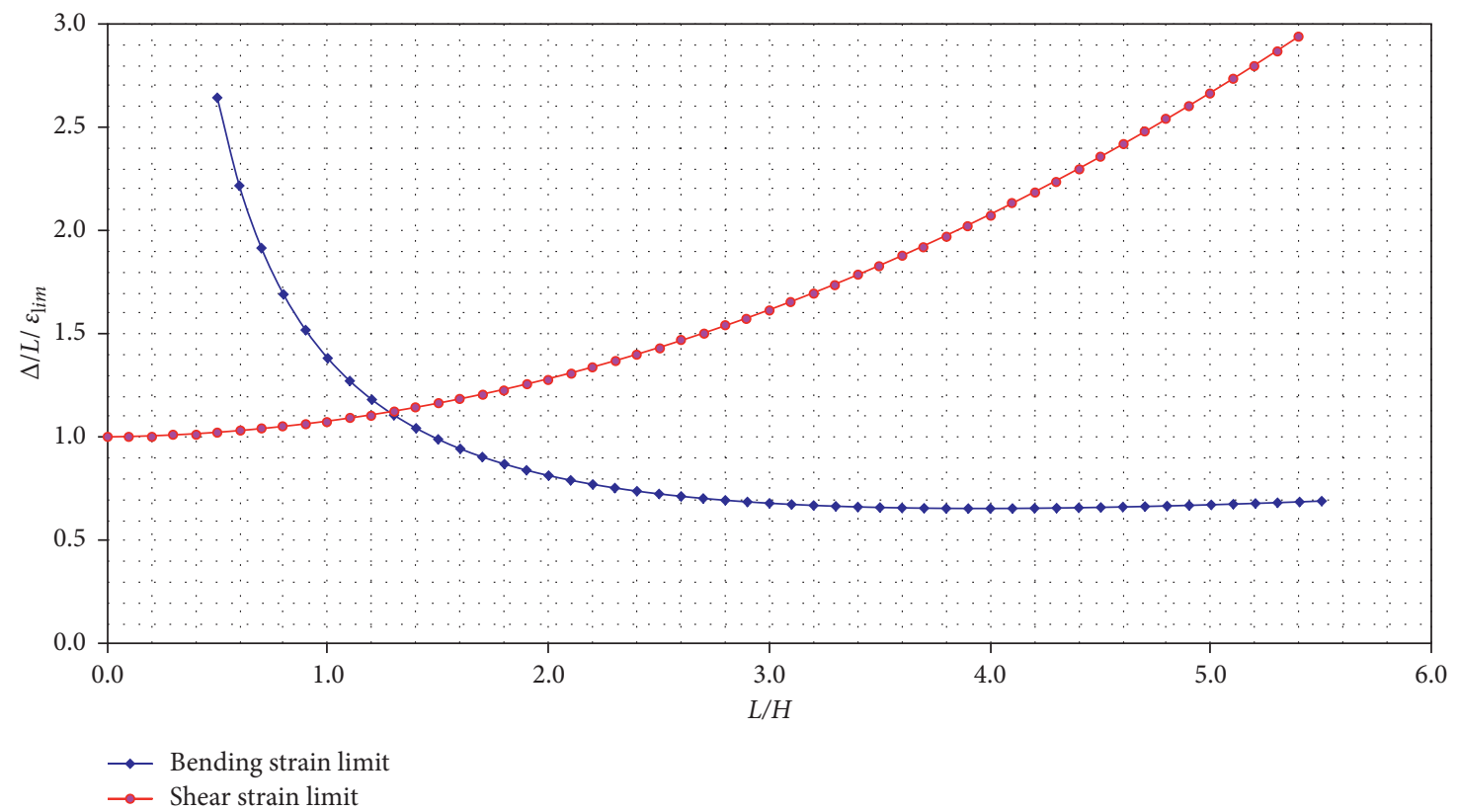

Figure 6: Relationship between $(\Delta / L) / \varepsilon_{\text {lim }}$ and $L / H$ for rectangular isotropic beams (hogging).

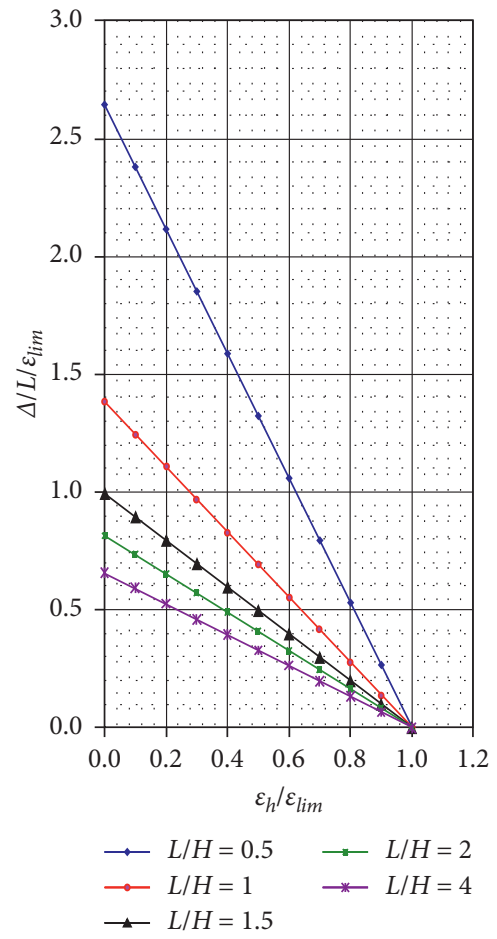

(a)

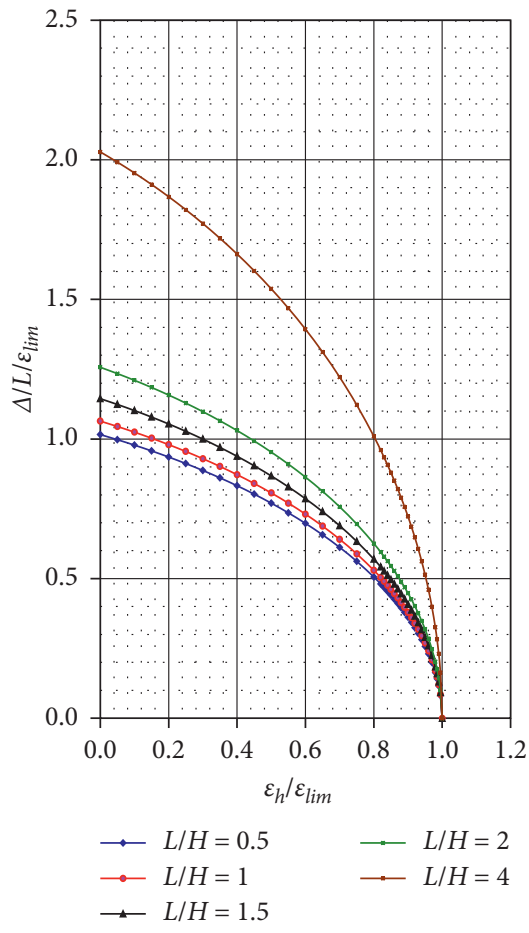

(b)

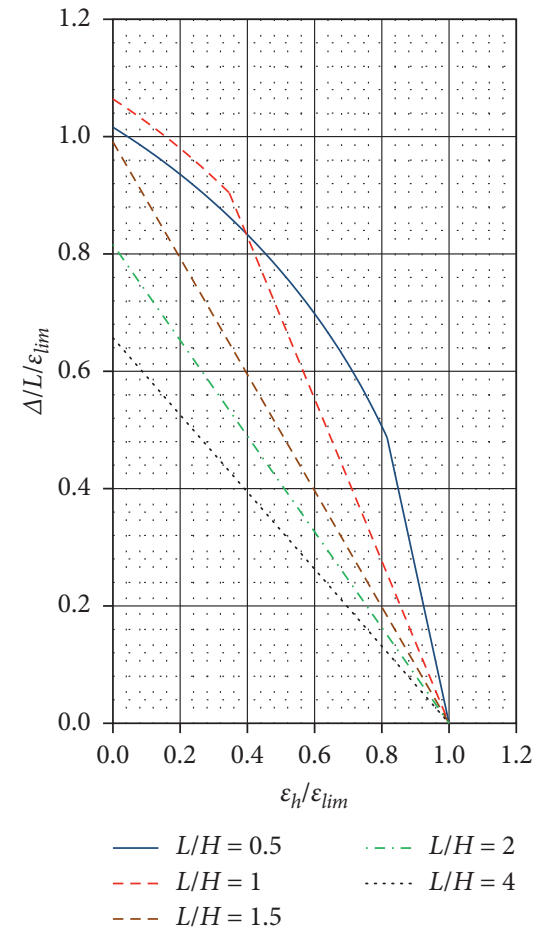

(c)

Figure 7: Relationship between $(\Delta / L) / \varepsilon_{\text {lim }}$ and $\varepsilon_{h} / \varepsilon_{\text {lim }}$ for rectangular isotropic beams (hogging). (a) Bending limit. (b) Shearing limit. (c) Limiting combinations.

3.3.4. Damage Criterion Proposed by Boscardin and Cording [21]. Boscardin and Cording [21] produced similar diagrams relating category of damage to horizontal strain $\varepsilon_{h}$ and angular distortion $\beta$ (instead of deflection ratio $\Delta / L$ ). They expressed the relationship between angular distortion $\beta$ and deflection ratio $\Delta / L$ as 


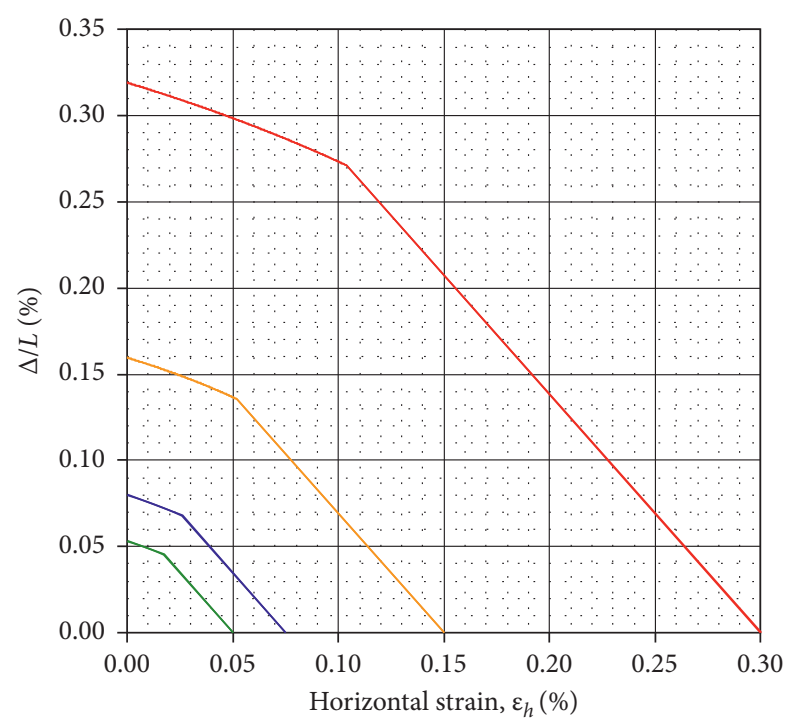

Figure 8: Damage interaction diagram for $L / H=1$ and hogging [22].

$$
\beta=\frac{3 \Delta}{L}\left[\frac{1+4(E / G)(H / L)^{2}}{1+6(E / G)(H / L)^{2}}\right] .
$$

Substitution of equation (7) into equation (6) yields

$$
\begin{aligned}
\frac{\beta}{\varepsilon_{\lim }}= & 3 \cdot\left[\frac{1+10.4(H / L)^{2}}{1+15.6(H / L)^{2}}\right] \cdot\left(1+0.064(L / H)^{2}\right) \\
& \cdot \sqrt{1-0.7 \frac{\varepsilon_{h}}{\varepsilon_{\lim }}-0.3\left(\frac{\varepsilon_{h}}{\varepsilon_{\lim }}\right)^{2}} .
\end{aligned}
$$

The damage interaction diagram corresponding to $L / H=1$ for isotropic beams $(E / G=2.6)$ undergoing hogging plotted according to equations (8) is shown in Figure 9. There are similarities between Figures 8 and 9 . However, the maximum bending strain $\varepsilon_{b \max }$ is ignored in Boscardin and Cording's [21] method. Burland et al. [22] have shown that the relationship between angular distortion $\beta$ and deflection ratio $\Delta / L$ is in fact very sensitive to the load distribution and to the value of $E / G$. Moreover, the precise evaluation of $\beta$ is not always straight forward and can be uncertain on occasions. The damage interaction diagrams for sagging after Burland and after Boscardin and Cording [21] can be deduced similarly by setting $h=H / 2$ and $I=H^{3} / 12$.

3.4. Selection of Appropriate Damage Criteria. As stated by Burland [24], it is not always straight forward to identify the tilt and the evaluation of angular distortion can sometimes be difficult. It is also very important not to confuse relative rotation $\beta$ with angular strain $\alpha$. For these reasons, Burland and Wroth [3] preferred the use of deflection ratio as a measure of building distortion. Therefore, in this paper, the damage criterion proposed by Burland et al. [22] is adopted. However, both the damage criteria proposed by Boscardin and Cording [21] and Burland et al. [22] are the most common ones and their selection shall be dependent on the convenience to obtain the relevant parameters.

3.5. Comments on the Application of Damage Criteria. A building can be considered separately as per its deflection mode to deformation on each side of the inflection point of the settlement profile (seen in Figure 3), which is used to partition the building. In a calculation of building strain, the building span length is required and is defined as the length of building in a hogging or sagging zone (shown as $L_{h}$ or $L_{s}$ in Figure 3). And it is advisable to treat the parts of the building under hogging and under sagging as separated beam segments by calculating the respective deflection ratio $(\Delta / L)$ and the average horizontal strain $\left(\varepsilon_{h}\right)$. The level of risk of damage can then be determined by categorizing the point plotted in terms of the $(\Delta / L)-\varepsilon_{h}$ pair according to the category boundaries of the interaction diagram of damage.

\section{Case Study}

The aforementioned global procedure is applied in this section to evaluate the engineering design of the extension line construction of a metro project from $\mathrm{PK} 0+344.00$ to PK0 +407.00 (as seen in Figure 10) with the cut-and-cover/ top-down excavation method. Both the ground deformations and structural deformations and forces are calculated through numerical modelling via FLAC3D program which utilizes the finite difference method (FDM).

4.1. Case Introduction. Figure 10 presents the plan view of a metro project including the studied zone. The following computational stages in numerical analysis are performed in order to simulate construction sequences:

(1) Stage 1: initial stress state $\left(\sigma_{v}=\gamma z\right.$ and $\left.\sigma_{h}=K_{0} * \sigma_{v}\right)$

(2) Stage 2: activation of diaphragm wall (wished-inplace)

(3) Stage 3: activation of surcharge loads

(4) Stage 4: excavation step 1 to level $-2.9 \mathrm{~m}$ (note: level 0 refers to the ground surface)

(5) Stage 5: activation of roof slab with $0.9 \mathrm{~m}$ thickness

(6) Stage 6: backfill from roof slab till the ground surface (level 0)

(7) Stage 7: excavation step 2 to level $-6.2 \mathrm{~m}$

(8) Stage 8: activation of struts at level $-5.7 \mathrm{~m}$

(9) Stage 9: groundwater lowering inside excavation to level $-15.2 \mathrm{~m}$

(10) Stage 10: excavation step 3 to the bottom of invert with lowest point at level $-13.7 \mathrm{~m}$

(11) Stage 11: activation of invert

Figure 11 presents the three main buildings (1, 2, and 3 ) located, respectively, at $\mathrm{PK} 0+380, \mathrm{PK} 0+364$, and $\mathrm{PK} 0+350$ adjacent to the excavation zones. The three buildings have the same width $(L=48.0 \mathrm{~m})$ and height $(H=27.45 \mathrm{~m})$. The 


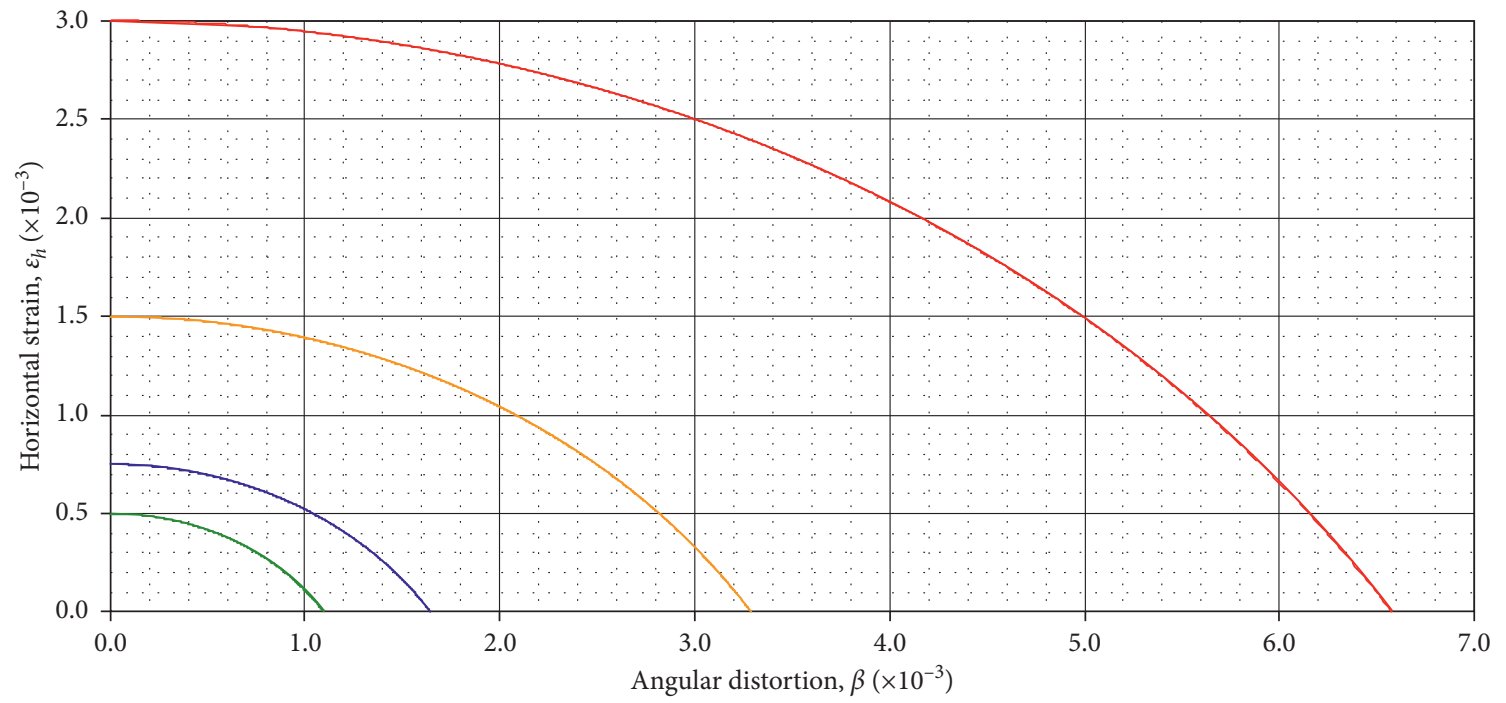

Figure 9: Damage interaction diagram for $L / H=1$ and hogging [21].

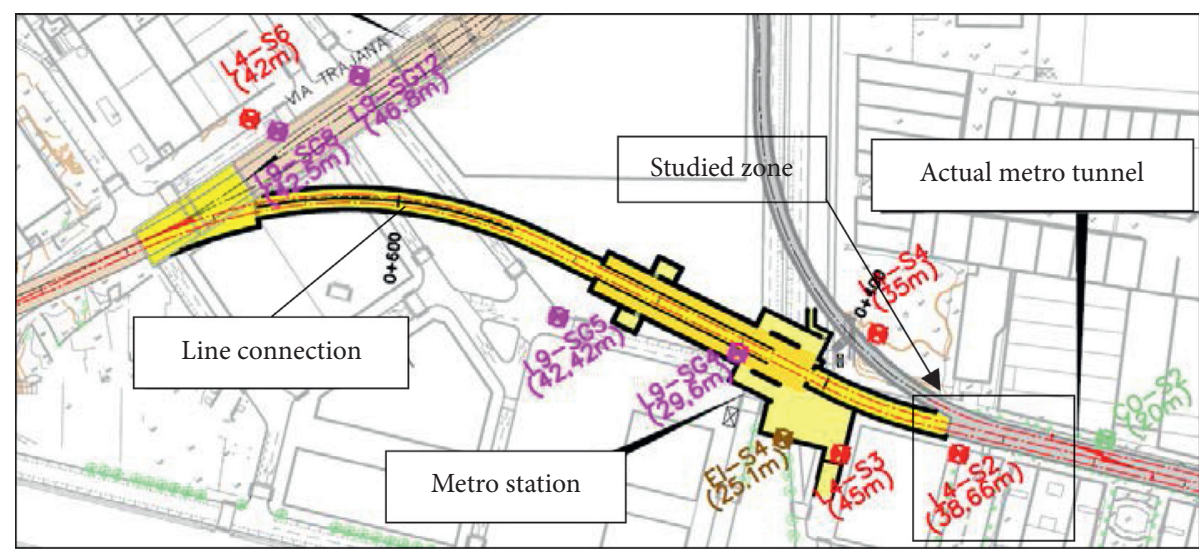

Figure 10: Plan view of a metro project.

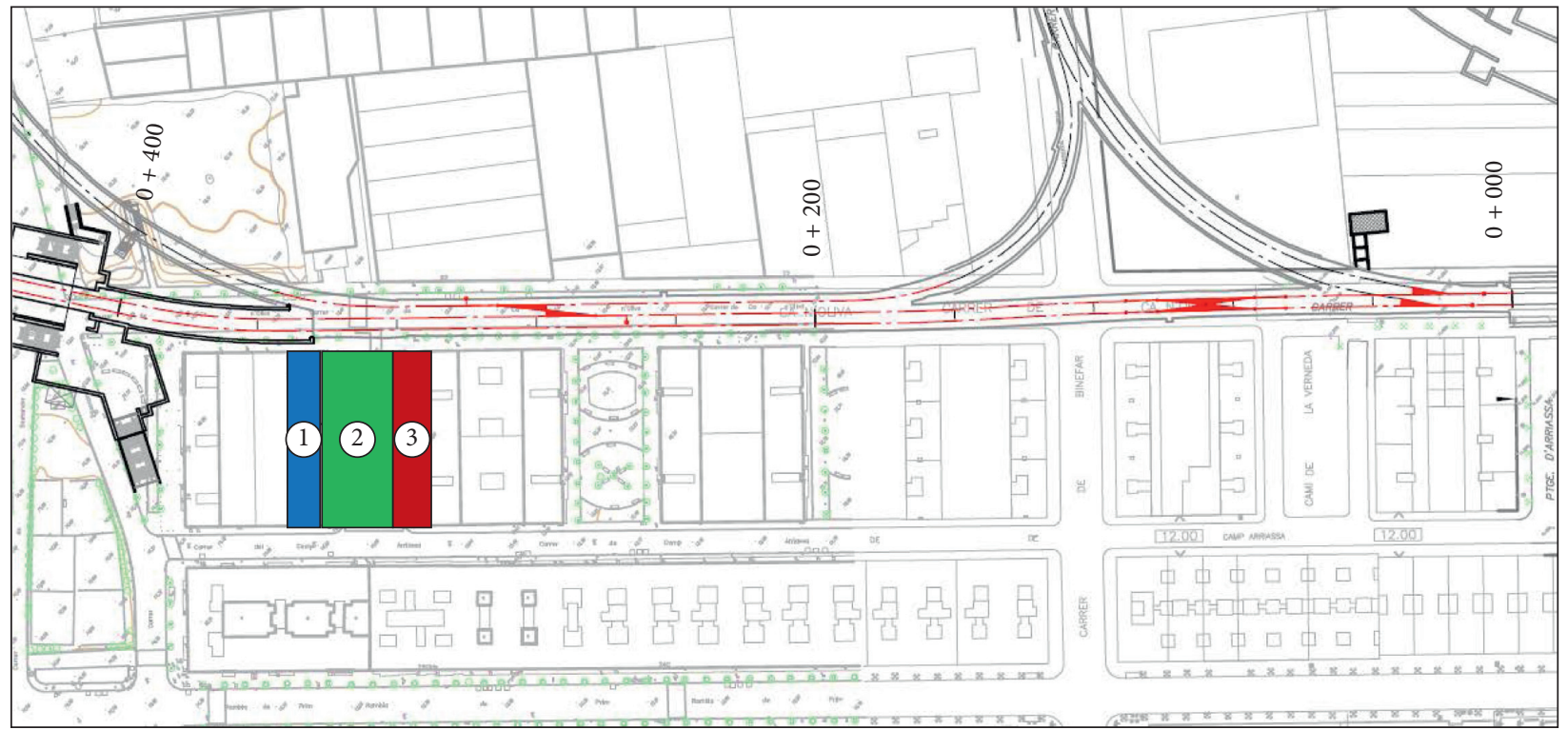

FIGURE 11: Buildings adjacent to the excavation. 
distances of the three buildings from the excavation centerline are individually $10.2 \mathrm{~m}, 10.4 \mathrm{~m}$, and $10.9 \mathrm{~m}$. With the design strategy, the evaluation of the potential damage of these three building should be made according to Burland criterion. Meanwhile, Boscardin criterion is also adopted to make comparisons with Burland criterion.

4.2. Description of Numerical Model. The numerical model is shown in Figure 12 including the mesh, soil profile, structural elements, and surcharges. The model is $63 \mathrm{~m}$ long along the longitudinal direction of metro line, and the right boundary is set to be at a distance of $100 \mathrm{~m}$ from the excavation centerline, which is sufficient because it is beyond the excavation influence zone (usually larger than 4 times the excavation depth, $\left(H_{e}=13.7 \mathrm{~m}\right)$ and the bottom at $43.7 \mathrm{~m}$ below the ground, and the bottom is set at a distance of $43.7 \mathrm{~m}$ below the ground surface. The model has totally 511296 nodes and 489510 zones.

In this model, the slightly curved metro line is simplified as a straight line and the diaphragm walls with little variable lengths are assumed to bear the same length $(19.7 \mathrm{~m})$-the lowest value of wall length which theoretically produces conservative results.

Only half of the whole excavation geometry is considered in the numerical model by assuming symmetry conditions on the centerline of the excavation. The assumption of symmetry condition is due to the following considerations: (a) this case study is mainly to present an example to show how to apply this method for real problem; (b) in reality, it is really difficult to have absolute symmetry condition. As a good practice, in many real projects, this kind of assumption may save time and encourage the engineers to adopt advanced analysis methods such as this one.

The soil profile comprises backfill, silty clay, and silty clay with sand and gravel. In Figure 11, backfill denotes the existent backfill before excavation while backfill2 refers to the newly added soil material above the roof slab. Backfill1 and backfill 2 are supposed to have the same properties. Silty clay and silty clay with sand and gravel are divided individually into two groups: silty clay1/silty clay2 and silty clay with sand and gravel1/silty clay with sand and gravel 2 by adopting two different values of elastic modulus which depends on the soil depth. All the soils are simulated with a hardening soil model-CYSoil model [14] in FLAC3D which has been proved to be capable of calculating realistic ground settlement profile. Table 2 presents the corresponding soil parameters for CYSoil model whose definitions can be referred to Itasca [14].

The $0.9 \mathrm{~m}$-thick roof slab and the $0.4 \mathrm{~m}$-thick invert are modelled as volumetric elements via linear elastic model. Table 3 gives the corresponding model parameters for roof slab and invert. Liner elements are applied to simulate the diaphragm walls whose parameters are given in Table 4 in which the liner interface properties are also presented. Struts are simulated via beam elements with the corresponding parameters shown in Table 5.

The permanent surcharge of $10 \mathrm{kPa}$ is set on the ground surface within $5.8 \mathrm{~m}$ distance from the diaphragm walls and between $54.5 \mathrm{~m}$ distance from the wall and the far side of the model. The variable surcharge of $60 \mathrm{kPa}$ due to building weights is set on the ground surface between $5.8 \mathrm{~m}$ distance and $54.5 \mathrm{~m}$ distance from the wall. This combination of surcharges is a simplification of the real surcharge conditions.

Symmetry boundary conditions are set on the left boundary, i.e., the excavation centerline. Horizontal displacements are fixed on the other three vertical boundaries (right, front, and behind). Both horizontal and vertical displacements are restrained on the bottom of the model.

The initial stress state is calculated with the $K_{0}$ method [14]. The initial phreatic surface is located at level $-8.2 \mathrm{~m}$. At stage 9 , the groundwater inside excavation is lowered to level $-15.2 \mathrm{~m}$.

4.3. Results. Stage 10 is the most unfavorable. Therefore, the results including the ground movement profiles at stage 10 are used to make the evaluation.

4.3.1. Representative Profiles of Ground Movements. The transversal section is selected at the middle of the numerical model along $Y$ axis so as to establish the representative profiles of ground movements adjacent to the excavation. Figure 13 presents the ground settlement profile, and Figure 14 shows the profile of horizontal ground displacement. In Figure 13, the ground settlement profile predicted from the empirical method proposed by Hsieh and $\mathrm{Ou}$ [6] is also exhibited by taking the maximum settlement the same as that calculated from FLAC3D. In this way, the distribution shape of the ground settlement obtained from FLAC3D could be checked by comparison with that predicted from the empirical method. It is evident that the ground settlement profile calculated via FLAC3D is similar to the predicted one which is constituted by linear segments and cannot capture the curvature of ground settlement profile and the inflection points. However, such ground settlement profile with curvature and inflection points can be acquired from FLAC3D.

As seen in Figure 13, the building is divided into three parts by points $\mathrm{E}, \mathrm{F}, \mathrm{G}$, and $\mathrm{H}$ in line with the inflection points $i 1$ where the derivative of the horizontal displacement is zero (as seen in Figure 15 at point $N$ ). The parts EF and FG are under sagging and the part $\mathrm{GH}$ is under hogging.

4.3.2. Evaluation of Risk of Building Damage. In Figure 13, $L_{h 1}, L_{s 1}$, and $L_{s 2}$ denote the lengths of the three parts of building. $\Delta_{\max \_h 1}, \Delta_{\max _{-} s 1}$, and $\Delta_{\max _{s} s 2}$ are the corresponding maximum relative deflections. In addition, the horizontal displacements at points $\mathrm{E}-\mathrm{H}$ are denoted by $\delta_{x E}$, $\delta_{x F}, \delta_{x G}$, and $\delta_{x H}$. Therefore, the risk of building damage of each part is then evaluated separately by calculating the respective deflection ratio $(\Delta / L)$ and average horizontal strain $\left(\varepsilon_{h}=\left(\delta_{x j}-\delta_{x k} / L\right)\right)$ under the corresponding $L / H$ where the superscripts $j$ and $k$ denote the division endpoints (E, F, F, and $\mathrm{H}$ ) of the building. 


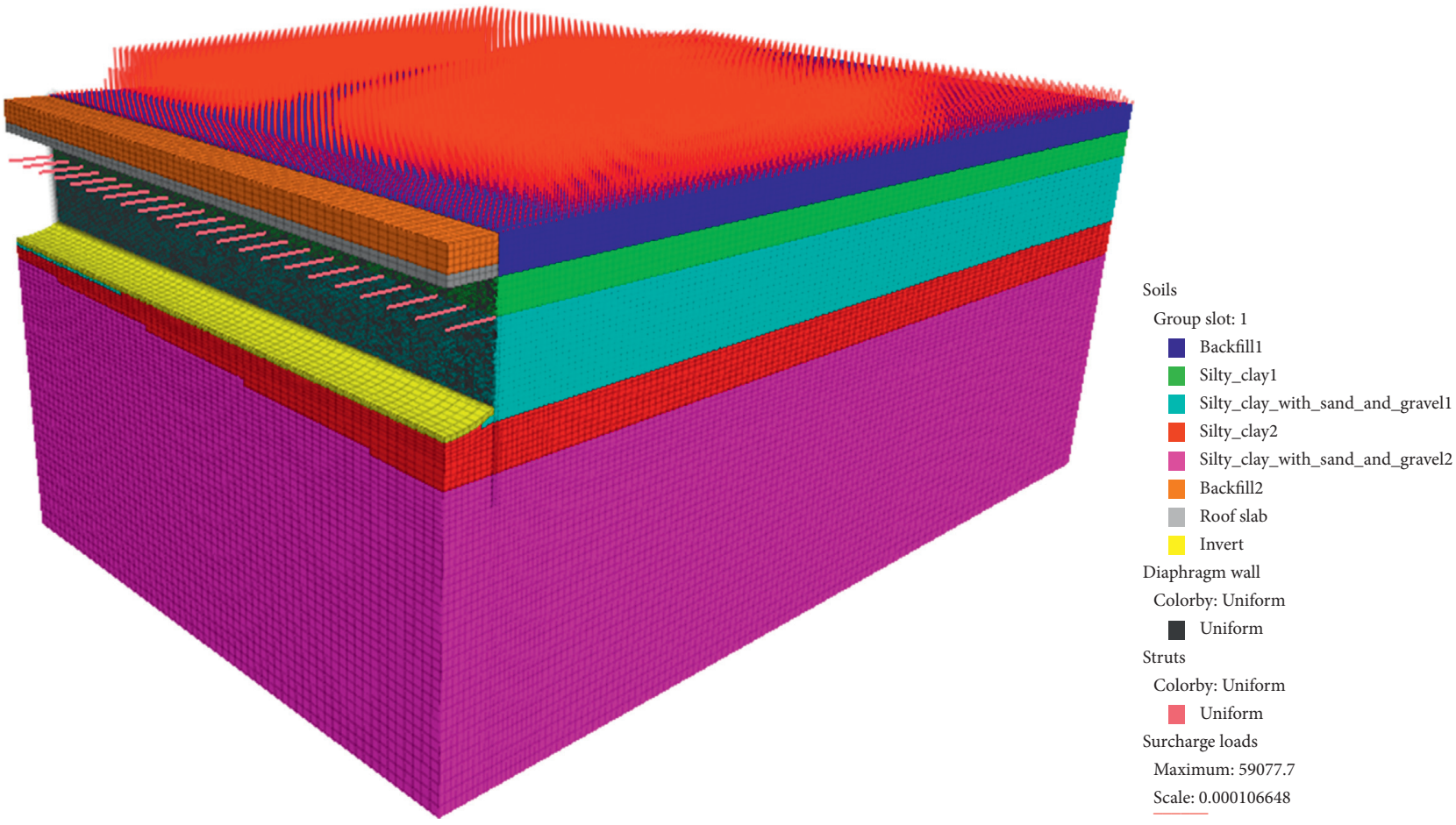

Figure 12: Numerical model in FLAC3D.

TABle 2: Soil parameters for CYSoil model.

\begin{tabular}{|c|c|c|c|c|c|}
\hline \multirow{2}{*}{ Property } & \multicolumn{5}{|c|}{ Soil type } \\
\hline & Backfill & Silty clay 1 & Silty clay with sand and gravel1 & Silty clay2 & Silty clay with sand and gravel2 \\
\hline$\gamma\left(\mathrm{kN} / \mathrm{m}^{3}\right)$ & 17.00 & 21.00 & 21.00 & 21.00 & 21.00 \\
\hline Porosity $n$ & 0.3 & 0.3 & 0.3 & 0.3 & 0.3 \\
\hline Permeability $k(\mathrm{~m} / \mathrm{s})$ & $2.0 e-5$ & $1.2 e-8$ & $7.7 e-2$ & $1.2 e-8$ & $7.7 e-2$ \\
\hline$K_{0}$ & 0.5 & 0.531 & 0.515 & 0.531 & 0.515 \\
\hline$E_{u r}^{r e f}(\mathrm{MPa})$ & 24.0 & 27.0 & 33.0 & 30.0 & 62.3 \\
\hline$E_{\text {oed }}^{\text {ref }}(\mathrm{MPa})$ & 8.0 & 9.0 & 11.0 & 10.0 & 20.8 \\
\hline$v_{u r}$ & 0.2 & 0.2 & 0.2 & 0.2 & 0.2 \\
\hline$K_{\mathrm{ref}}^{\mathrm{iso}}(\mathrm{MPa})$ & 8.0 & 9.0 & 11.0 & 10.0 & 20.8 \\
\hline$G_{r e f}^{e}(\mathrm{MPa})$ & 10.0 & 11.3 & 13.8 & 12.5 & 26.0 \\
\hline$\alpha$ & 1 & 1 & 1 & 1 & 1 \\
\hline$c(\mathrm{MPa})$ & 0 & 0 & 0 & 0 & 0 \\
\hline$\phi_{f}\left({ }^{\circ}\right)$ & 30 & 28 & 29 & 28 & 29 \\
\hline$\phi_{\text {ini }}\left({ }^{\circ}\right)$ & 19.5 & 17.8 & 18.7 & 17.8 & 18.7 \\
\hline$\psi_{f}\left({ }^{\circ}\right)$ & 0 & 0 & 0 & 0 & 0 \\
\hline$R$ & 0.67 & 0.67 & 0.67 & 0.67 & 0.67 \\
\hline$p_{\text {ref }}(\mathrm{MPa})$ & 0.1 & 0.1 & 0.1 & 0.1 & 0.1 \\
\hline$m$ & 1 & 1 & 1 & 1 & 1 \\
\hline$R_{f}$ & 0.9 & 0.9 & 0.9 & 0.9 & 0.9 \\
\hline
\end{tabular}

TABLE 3: Model parameters of roof slab and invert.

\begin{tabular}{lcccc}
\hline Structural element & Constitutive model & $E(\mathrm{GPa})$ & $\nu$ & $\gamma\left(\mathrm{kN} / \mathrm{m}^{3}\right)$ \\
\hline Roof slab and invert & Linear elastic & 29.80 & 0.15 & 25.0 \\
\hline
\end{tabular}

TABle 4: Model parameters of diaphragm walls.

\begin{tabular}{lcccccccccc}
\hline Structural element & Constitutive model & Thickness $(\mathrm{m})$ & Length $(\mathrm{m})$ & $\gamma\left(\mathrm{kN} / \mathrm{m}^{3}\right)$ & $\nu$ & $K_{n}(\mathrm{~Pa})$ & $K_{s}(\mathrm{~Pa})$ & $\phi\left({ }^{\circ}\right)$ & $C_{s}(\mathrm{~Pa})$ & $C_{s}-\mathrm{res}(\mathrm{Pa})$ \\
\hline Diaphragm walls & Liner & 0.8 & 19.7 & 25.0 & 0.15 & $5 \mathrm{e} 9$ & $5 \mathrm{e} 9$ & 20.0 & $5 \mathrm{e} 6$ & $5 \mathrm{e} 3$ \\
\hline
\end{tabular}


TABLE 5: Model parameters of struts.

\begin{tabular}{lcccccccc}
\hline Structural element & Constitutive model & $E(\mathrm{GPa})$ & $v$ & $\gamma\left(\mathrm{kN} / \mathrm{m}^{3}\right)$ & Area $\left(\mathrm{m}^{2}\right)$ & $I_{x x}\left(\mathrm{~m}^{4}\right)$ & $I_{y y}\left(\mathrm{~m}^{4}\right)$ & $\mathrm{Spacing}_{(\mathrm{m})}$ \\
\hline Struts & Beam & 29.80 & 0.2 & 25.0 & 0.25 & 0.00521 & 0.00521 & 2.50 \\
\hline
\end{tabular}

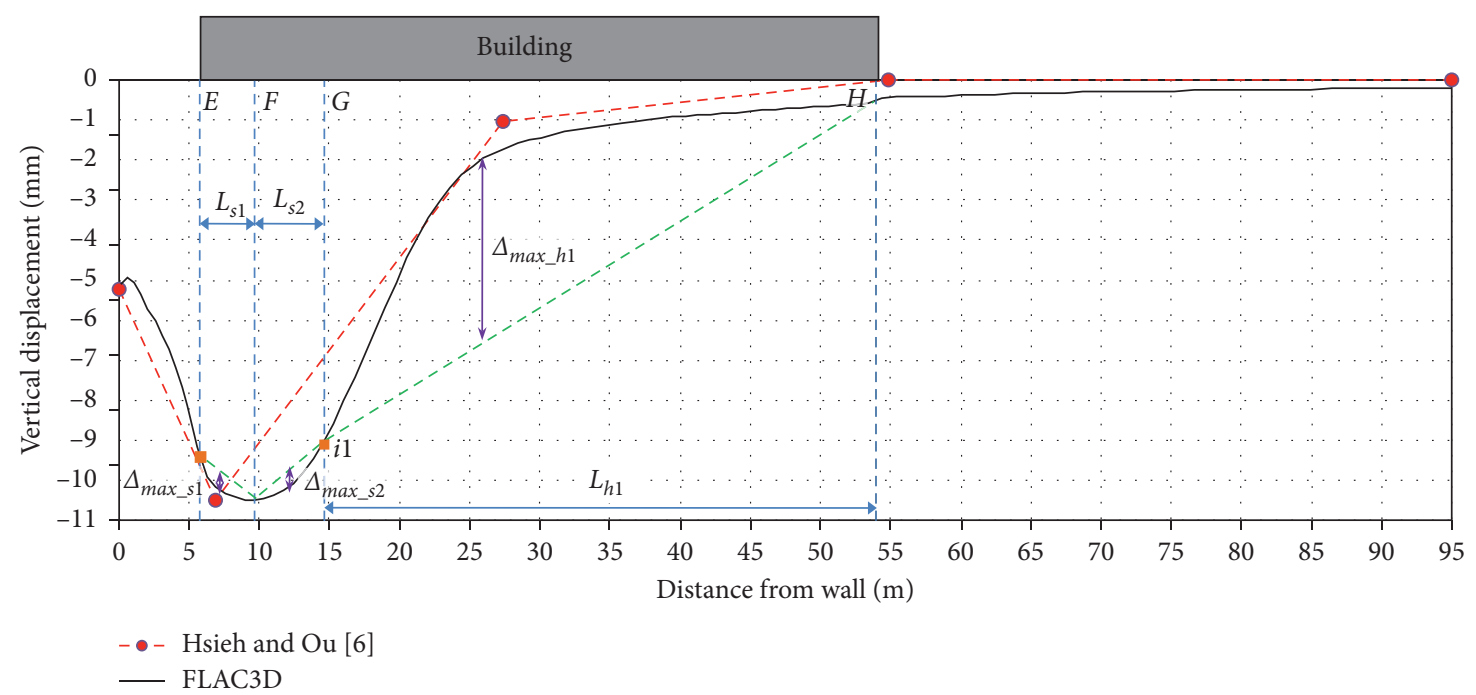

Figure 13: Profiles of ground settlement.

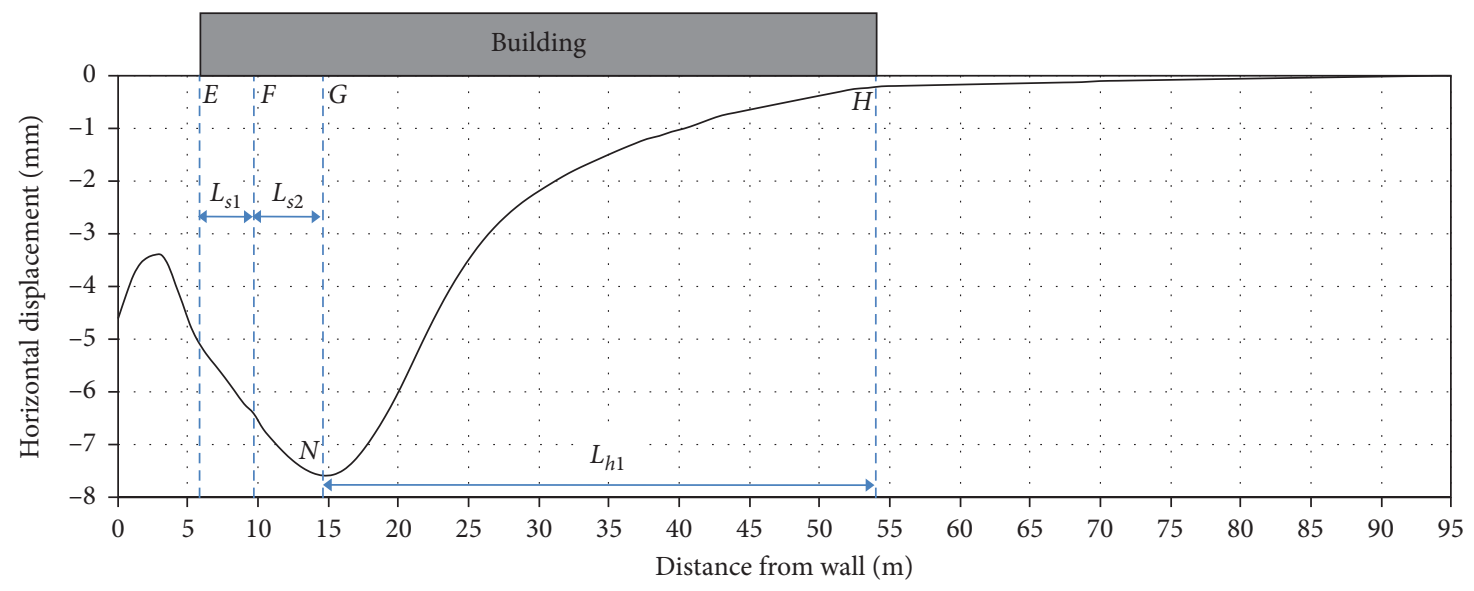

- FLAC3D

FIgURe 14: Profiles of horizontal ground displacement.

The results of damage risk evaluation for buildings 1-3 are shown in Table 6 . The point of $(\Delta / L)-\varepsilon_{h}$ pair is plotted in the relevant interaction diagram of damage for each division of each building (seen in Figure 15). It should be pointed out that the absolute values of $(\Delta / L)-\varepsilon_{h}$ pair are used to make these plots. The shape of damage interaction diagram for each $L / H$ ratio is firstly determined by selecting the lowest bounding limits of the combination of bending limiting and shearing limiting as shown in Figure 7(c).

It can be seen from Figure 15 that all the points of $(\Delta / L)-\varepsilon_{h}$ pair for each part of the three buildings are within category level 0 implying the low risk of damage for all the three buildings induced by the excavations. Therefore, the engineering design of a metro project from $\mathrm{PK} 0+344.00$ to 


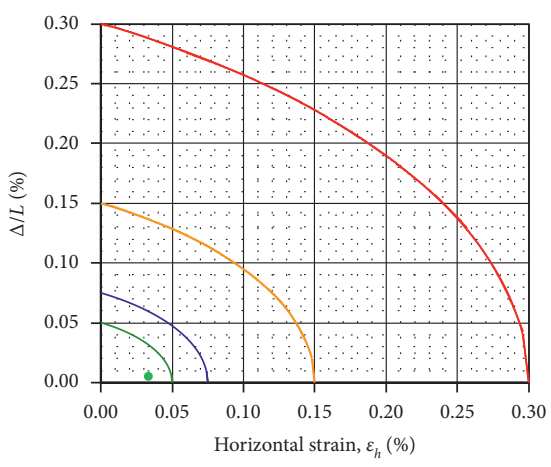

- Part1 of building $1(\mathrm{PK} 0+380)$

(a)

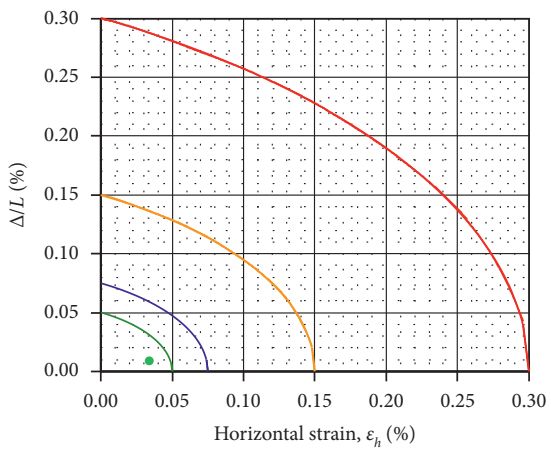

- Part1 of building 2 (PK0 + 364)

(d)

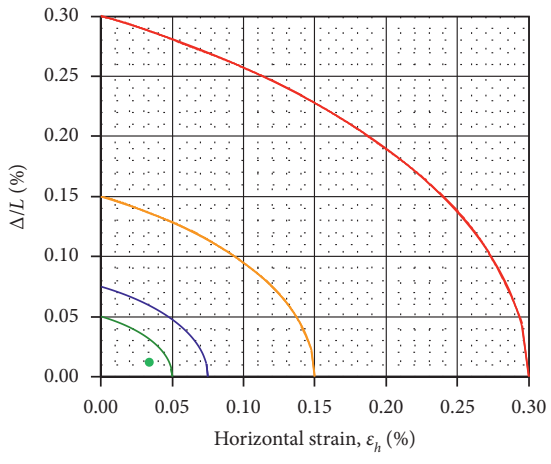

- Partl of building $3(\mathrm{PK} 0+350)$

(g)

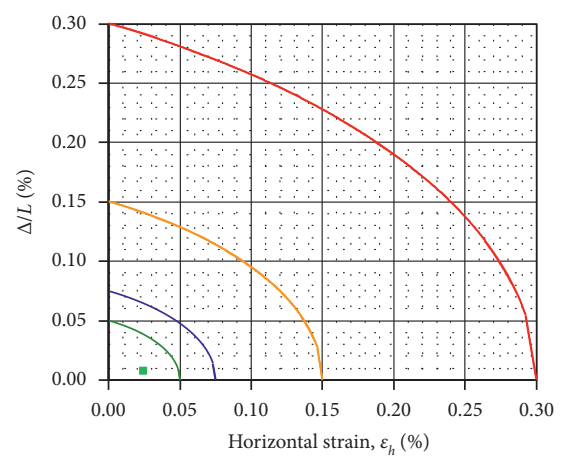

- Part2 of building $1(\mathrm{PK} 0+380)$

(b)

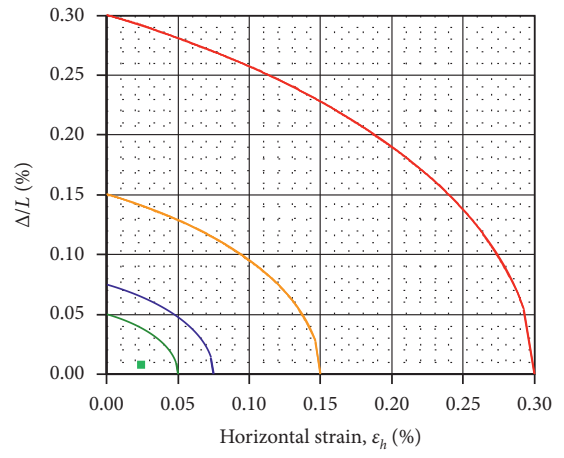

- Part2 of building $2(\mathrm{PK} 0+364)$

(e)

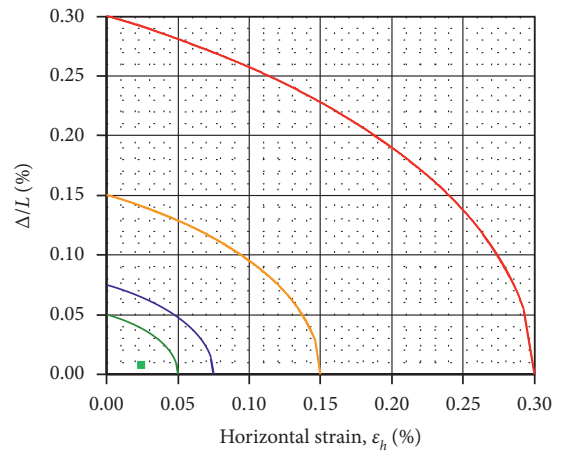

- Part2 of building $3($ PK0 +350$)$

(h)

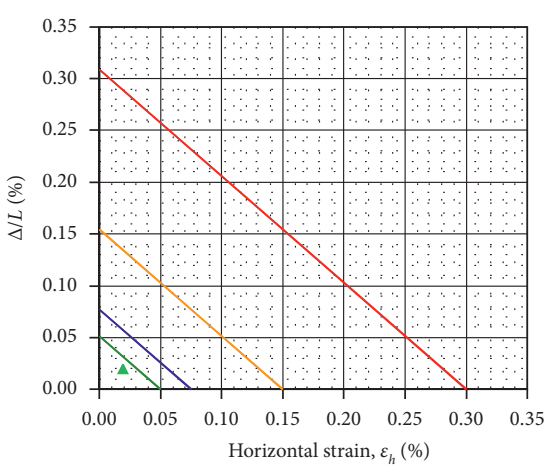

4 Part3 of building $1(\mathrm{PK} 0+380)$

(c)

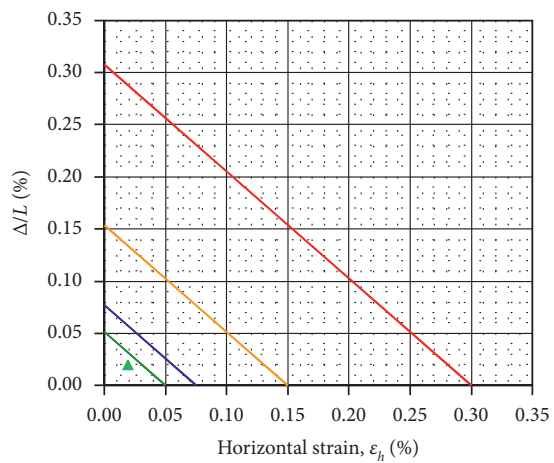

4 Part3 of building $2(\mathrm{PK} 0+364)$

(f)

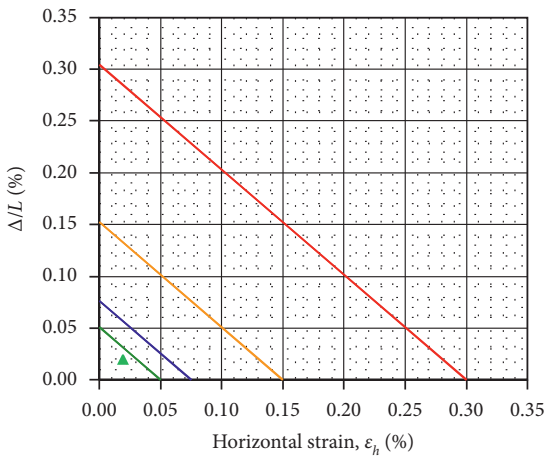

$\Delta$ Part3 of building 3 (PK0 +350$)$

(i)

Figure 15: Damage interaction diagrams with points of $(\Delta / L)-\varepsilon_{h}$ pair. 


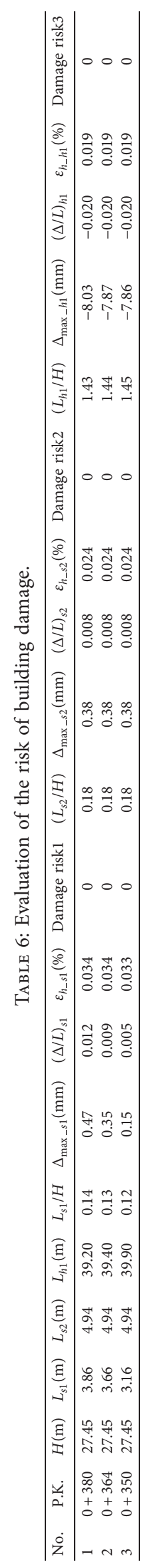


PK0 +407.00 is acceptable while considering the risk of damage to buildings due to deep excavations.

\section{Conclusions and Recommendations}

This paper puts forward a 4-step procedure to justify the engineering design in view of the risk of damage to buildings due to deep excavations. Firstly, the ground movement profiles induced by excavations are obtained from numerical modelling via numerical software such as FLAC3D and at the same time verified by empirical results. Secondly, the appropriate damage criterion proposed by Burland et al. [22] is adopted. Thirdly, the buildings adjacent to the excavations are partitioned by building endpoints and inflection points. Meanwhile, for each division of each building, $\Delta / L$ and $\varepsilon_{h}$ are calculated from the ground settlement and horizontal displacement profiles and plotted in the interaction diagram of damage. The risk level of building damage is then classified according to the domain of the point of $(\Delta / L)-\varepsilon_{h}$ pair. Fourthly, the corresponding engineering design is justified in line with the magnitude of ground movements and the risk level of building damage. The 4-step procedure should be cycled until the magnitude of ground movements and the risk level of building damage with the current engineering design are within the range of engineering safety.

By adopting this procedure, the engineering design of a metro project between $\mathrm{PK} 0+344.00$ and $\mathrm{PK} 0+407.00$ is justified to be acceptable considering that the damage risk levels of all the buildings adjacent to the excavations are within category level 0 and the magnitude of ground movement is within the range of engineering safety.

This procedure provides a way to estimate and evaluate quantitatively the damage risk of adjacent buildings due to deep excavation in the stage of engineering design. However, while applying it, attention shall be paid to the following considerations:

(1) The appropriate soil constitutive model shall be adopted based on the soil behavior.

(2) Proper model parameters, boundary conditions, and techniques shall be used.

(3) Hogging and sagging parts of the calculated ground profile shall be divided correctly.

(4) The parameters used in damage interaction diagram shall be understood clearly and calculated correctly considering $\mathrm{L} / \mathrm{H}$ ratio.

(5) Both Burland and Boscardin criteria are applicable and the use of which one is dependent on the convenience to acquire the relevant parameters.

However, the field ground movement profiles observed in the construction stage should be compared with the calculated ground movement profiles in the design stage to verify its reasonableness.

Finally, it shall be pointed out that the risk level assessment of building damage induced by deep excavations is only one aspect of justification of the engineering design. The other aspects such as analyses of stress and deformation, internal and external stability, water flow and piping, and analyses of structure safety should also be considered in order to justify the relevant design strategy.

\section{Data Availability}

The data used to support the findings of this study are available from the corresponding author upon request.

\section{Conflicts of Interest}

The authors declare that they have no conflicts of interest.

\section{Acknowledgments}

This research was financially supported by the Science and Technology Research Program of Chongqing Municipal Education Commission (no. KJQN202001343), the Science and Technology Research Program of Chongqing University of Arts and Sciences (no. R2019STM09), the Industrial Cooperative Education Program of Ministry of Education of the People's Republic of China (no. 201902133039), the Major Cultivation of Natural Science Research Program of Chongqing University of Arts and Sciences (no. P2020TM15), and the Guide Science and Technology Research Program of Chongqing Civil Engineering and Architecture Society (no. 2021A05).

\section{References}

[1] J. B. Burland, J. R. Standing, and F. M. Jardine, Building Response to Tunnelling. Case Studies from the Jubilee Line Extension, London, 1, Projects and Methods, CIRIA and Thomas Telford, London, UK, 2001.

[2] J. B. Burland, J. R. Standing, and F. M. Jardine, Building Response to Tunnelling. Case Studies from the Jubilee Line Extension, London, 2, Case Studies, CIRIA and Thomas Telford, London, UK, 2001.

[3] J. B. Burland and C. P. Wroth, Settlement of Buildings and Associated Damage, Cambridge Pentech Press, Cambridge, UK, 1974.

[4] R. B. Peck, "Deep excavation and tunneling in soft ground," in Proceedings of the 7th International Conference on Soil Mechanics and Foundation Engineering, pp. 225-290, Mexico City, Mexico, June 1969.

[5] G. W. Clough and T. D. O'Rourke, "Design and performance of earth retaining structures," Construction Induced Movements of In-Situ Walls, ASCE Geotechnical Special Publication 25, New York, NY, USA, 1990.

[6] P.-G. Hsieh and C.-Y. Ou, "Shape of ground surface settlement profiles caused by excavation," Canadian Geotechnical Journal, vol. 35, no. 6, pp. 1004-1017, 1998.

[7] H. F. Schweiger, "Results from numerical benchmark exercises in geotechnics," in Proceedings of the 5th European Conference Numerical Methods in Geotechnical Engineering, pp. 305-314, Presses Ponts et Chaussees, Paris, France, September 2002.

[8] H. F. Schweiger, "Benchmarking in geotechnics, part I: results of benchmarking. part II:reference solution and parametric study," Technical report CGG IR006, Institute for Soil 
Mechanics and Foundation Engineering, Graz University of Technology, Graz, Austria, 2002.

[9] H. F. Schweiger, PLAXIS Benchmark No. 2: Excavation 1: Results.PLAXIS Users Association, Delft, Netherlands, 2003.

[10] H. F. Schweiger, "Results from the ERTC7 benchmark exercise," in Proceedings of the 6th European Conference Numerical Methods in Geotechnical Engineering, pp. 3-8, Taylor \& Francis, Graz, Austria, September 2006.

[11] H. F. Schweiger, "Modelling issues for numerical analysis of deep excavations," in Proceedings of the 2007 Özel Konulu Sempozyum: Teori ve Uygulamada Zemin-Yapı Etkileşimi, pp. 15-25, Istanbul, Turkey, November 2007.

[12] H. F. Schweiger, "Influence of constitutive model and EC7 design approach in fem analysis of deep excavations," in Proceedings of the 2009 ISSMGE International Seminar on Deep Excavations and Retaining Structures, pp. 99-114, Budapest, Hungary, May 2009.

[13] H. F. Schweiger, "Design of deep excavations with FEM-influence of constitutive model and comparison of EC7 design approaches," in Proceedings of the 2010 Earth Retention Conference, pp. 804-817, Geotechnical Special Publication, Bellevue, WA, USA, April 2010.

[14] Itasca Consulting Group Inc, FLAC3D_Fast Lagrangian Analysis of Continua in 3 Dimensions, Itasca Consulting Group, Minneapolis, MN, USA, 2009.

[15] R. J. Finno and M. Alvello, "Analysis and performance of the excavation for the Chicago-state subway renovation project and its effects on adjacent structures," Technical report, Department of Civil Engineering, Northwestern University, Evanston, IL, USA, 2002.

[16] A. W. Skempton and D. H. MacDonald, "The Allowable Settlements of Buildings," Proceedings of the Institution of Civil Engineers, vol. 5, no. 6, pp. 727-768, 1956.

[17] D. E. Polshin and R. A. Tokar, "Maximum allowable nonuniform settlement of structures," in Proceedings of the 4th International Conference on Soil Mechanics and Foundation Engineering, vol. 1, p. 402, London, UK, August 1957.

[18] L. Bjerrum, "Discussion on compressibility of soils," in Proceedings of the 1963 European Conference on Soil Mechanics and Foundation Engineering, vol. 2, pp. 26-27, Wiesbaden, Germany, September 1963.

[19] T. D. O’Rourke, E. J. Cording, and M. Boscardin, “The ground movements related to braced excavation and their influence on adjacent buildings," Report no. DOT-TST 76T-23, U.S. Department of Transportation, Washington, DC, USA, 1976.

[20] P. B. Atterwell, J. Yeates, and A. R. Selby, Soil Movements Induced by Tunnelling and Their Effects on Pipelines and Structures, US Department of Energy, Washington, DC, USA, 1986.

[21] M. D. Boscardin and E. J. Cording, "Building response to excavation-induced settlement," Journal of Geotechnical Engineering, vol. 115, no. 1, pp. 1-21, 1989.

[22] J. B. Burland, R. J. Mair, and J. R. Standing, "Ground performance and building response to tunnelling," in Proceedings of the 2004 International Conferenceon Advances in Geotechnical Engineering, vol. 1, pp. 291-342, March 2004.

[23] J. B. Burland, J. B. Broms, and V. F. B. De Mello, "Behavior of foundations and structures. SOA report session 2," in Proceedings of the 9th International Conference on Soil Mechanics and Foundation Engineering, vol. 2, pp. 495-546, Tokyo, Japan, July 1977.

[24] J. B. Burland, "The assessment of the risk of damage to buildings due to tunnelling and excavation," in Movimientos de Edificios Inducidos por Excavaciones: Criterios de Daño y
Destión del RiesgoEscola Tècnica Superior d'Enginyers de Camins, Canals i Ports de Barcelona, Universitat Politècnica de Catalunya, Barcelona, Spain, 2008.

[25] S. Timoshenko, Strength of Materials-Part I, D van Nostrand Co, Inc., New York, NY, USA, 1957. 